\title{
Intravenously administered cloxacillin- induced neutropenia with eosinophilia in a patient with infective endocarditis: a case report
}

\author{
J. A. A. S. Jayaweera ${ }^{1,2^{*}}$, W. P. H. Abeydeera ${ }^{2}$ and G. R. Ranasinghe ${ }^{2}$
}

\begin{abstract}
Background: Bacteremia following Staphylococcus aureus is a serious clinical condition which is often associated with distant metastatic infections. One of the most dreaded complications of Staphylococcus aureus bacteremia is infective endocarditis. Cloxacillin is a common antibiotic prescribed for suspected staphylococcal infections and confirmed methicillin-sensitive Staphylococcus aureus infections. Prolonged use of cloxacillin may lead to neutropenia.
\end{abstract}

Case presentation: A 38-year-old Sinhalese man presented to Teaching Hospital Kurunegala, Sri Lanka, complaining of a 3-week history of fever; he was found to have a pansystolic murmur over the apex of his heart. He had leukocytosis with predominant neutrocytosis. His C-reactive protein was $231 \mathrm{mg} / \mathrm{l}$ and erythrocyte sedimentation rate was $100 \mathrm{~mm} /$ first hour. Transthoracic two-dimensional echocardiography revealed prolapsed mitral valve with $7 \times 13 \mathrm{~mm}$ vegetation over the posterior mitral valve. On the following day, three blood cultures became positive and were subsequently identified as Staphylococcus aureus. Intravenously administered cloxacillin $3 \mathrm{~g} 6$ hourly was started. Following day 24 of intravenously administered cloxacillin, our patient developed high spike fever. His total white blood cells were: $990 / \mathrm{mm}^{3}$ with $34 \%$ neutrophils and $22 \%$ eosinophils. His hemoglobin concentration was $9.5 \mathrm{~g} / \mathrm{dL}$ and platelet count remained normal $\left(202 \times 10^{6} / \mathrm{mm}^{3}\right)$. His C-reactive protein was $78 \mathrm{mg} / \mathrm{l}$, erythrocyte sedimentation rate was $95 \mathrm{~mm} /$ first hour, and he was otherwise comfortable, showing no signs of sepsis beside the high grade fever. His serum was negative for filarial and Toxoplasma antibodies while stool was negative for oocytes and amoebic cysts. Further, his serum was negative for dengue virus, Epstein-Barr virus, cytomegalovirus, and hepatitis B antibodies. He was clinically well on day 6 after stopping cloxacillin with $44 \%$ neutrophils and 18\% eosinophils. His C-reactive protein and erythrocyte sedimentation rate became normal, and there was no further plan for cardiothoracic intervention or administration of antimicrobials. He was discharged from hospital and remained well 6 months later.

Conclusion: This case report signifies the potential fatal adverse effect of cloxacillin in methicillin-sensitive Staphylococcus aureus infections. Leukopenia is associated with prolonged use of high doses of cloxacillin. In addition to transthoracic two-dimensional echocardiography and inflammatory markers, sequential white blood cells and differential counts would help clinicians to assess the prognosis of patients with infective endocarditis.

Keywords: Infective endocarditis, Cloxacillin, Prolonged use, Agranulocytosis, Eosinophilia and risk for sepsis

\footnotetext{
*Correspondence: jaas820703@yahoo.com; jaas071@gmail.com

'Department of Microbiology Faculty of Medicine and Allied Sciences,

Rajarata University of Sri Lanka, Saliyapura, Sri Lanka

${ }^{2}$ Teaching Hospital Kurunegala, Kurunegala, Sri Lanka
}

(c) The Author(s). 2018 Open Access This article is distributed under the terms of the Creative Commons Attribution 4.0 International License (http://creativecommons.org/licenses/by/4.0/), which permits unrestricted use, distribution, and reproduction in any medium, provided you give appropriate credit to the original author(s) and the source, provide a link to the Creative Commons license, and indicate if changes were made. The Creative Commons Public Domain Dedication waiver (http://creativecommons.org/publicdomain/zero/1.0/) applies to the data made available in this article, unless otherwise stated. 


\section{Background}

Bacteremia following Staphylococcus aureus is a serious clinical condition which is often associated with distant metastatic infections [1, 2]. One of the most dreaded complications of Staphylococcus aureus bacteremia is infective endocarditis (IE), which has been reported to occur in $6-32 \%$ of these patients $[3,4]$.

Cloxacillin is one of several common antibiotics prescribed for suspected staphylococcal infections and confirmed methicillin-sensitive Staphylococcus aureus (MSSA) infections [5]. In IE, prolonged use of antimicrobials is advocated according to the guidelines of the Infectious Diseases Society of America; thus, it warrants complete cure of IE with minimal complications. However, prolonged (> 20 days) use of cloxacillin may lead to neutropenia [6]. In this case, prolonged use of cloxacillin in MSSA-associated IE led to neutropenia which is described here.

\section{Case presentation}

A 38-year-old Sinhalese man presented to Teaching Hospital Kurunegala in Sri Lanka complaining of a 3-week history of fever, lethargy, and fatigability. He had not had any significant clinical conditions prior to this. He did not have any food or drug allergies while he was on regular anti-worm and anti-filarial prophylaxis. On clinical examination, he was febrile $\left(39.4^{\circ} \mathrm{C}\right)$, pale, and found to have a pansystolic murmur over the apex of his heart. He had leukocytosis $\left(12.4 \mathrm{~mm}^{3}\right)$ with predominant neutrocytosis (81\%). His hemoglobin was $11.2 \mathrm{~g} / \mathrm{dL}$, C-reactive protein (CRP) was $231 \mathrm{mg} / \mathrm{l}$, and erythrocyte sedimentation rate (ESR) was $100 \mathrm{~mm} /$ first hour. Transthoracic two-dimensional echocardiography (echo) revealed grade II mitral regurgitation, myxomatous, prolapsed mitral valve with $7 \times 13 \mathrm{~mm}$ vegetation over the posterior mitral valve. Three sets of blood cultures were obtained within 1 hour from three different venipuncture sites; intravenously administered ceftriaxone was started empirically.

The following day, the three blood cultures became positive and were subsequently identified as Staphylococcus aureus. Intravenously administered cloxacillin $3 \mathrm{~g} 6$ hourly was initiated while ceftriaxone was omitted. The (72 hours following initial culture) clearance blood cultures revealed Staphylococcus aureus and repeated clearance cultures following 72 hours remained negative. From that day onwards, for duration of 42 days, intravenously administered cloxacillin therapy was determined while clinical response was monitored with quarter hourly temperature, transthoracic two-dimensional echo, white blood cell/differential counts (WBC/DC), CRP, and ESR (Table 1). Further, he was on acetaminophen and chlorpheniramine malate as required.

Following day 24 of intravenously administered cloxacillin, our patient developed high spike fever $\left(39.6^{\circ} \mathrm{C}\right)$ and his full blood count showed: WBC $990 / \mathrm{mm}^{3}$ with $34 \%$ of neutrophils and $22 \%$ eosinophils. His hemoglobin concentration was $9.5 \mathrm{~g} / \mathrm{dL}$, platelet count $\left(202 \times 10^{6} / \mathrm{mm}^{3}\right)$, D-dimer $(320 \mathrm{ng} / \mathrm{mL}$ fibrinogen equivalent units), and both prothrombin time (PT) and partial thromboplastin time (PTT) remained normal. His CRP was $78 \mathrm{mg} / \mathrm{l}$, ESR was $95 \mathrm{~mm} /$ first hour, and he was otherwise comfortable, showing no signs of sepsis beside the high grade fever. His vital signs (blood pressure and pulse) were normal. Repeat transthoracic two-dimensional echo was normal thus no vegetations were detected. Mild elevation of liver enzymes was observed and an ultrasound of his abdomen revealed no hepatomegaly: gamma-glutamyl transferase $192 \mathrm{IU} / \mathrm{ml}$, alanine transaminase (ALT) $15 \mathrm{IU} / \mathrm{ml}$, and alkaline

Table 1 Timeline: fluctuation of hematological parameters, inflammatory markers, and transthoracic two-dimensional echocardiography following intravenously administered cloxacillin treatment

\begin{tabular}{|c|c|c|c|c|c|c|c|c|c|}
\hline \multirow{3}{*}{$\begin{array}{l}\text { Parameter } \\
\text { Hematological }\end{array}$} & \multicolumn{9}{|l|}{ Timeline } \\
\hline & \multicolumn{4}{|c|}{ On IV cloxacillin therapy } & \multicolumn{5}{|c|}{ Omission of IV cloxacillin } \\
\hline & On admission & Day 12 & Day 17 & Day 22 & Day 24 & Day 26 & Day 30 & Day 32 & Day 34 \\
\hline $\mathrm{WBC} / \mathrm{mm}^{3}$ & 12.4 & 8.2 & 8.1 & 3.5 & 2.5 & 3.1 & 4.2 & 4.4 & 4.4 \\
\hline N (\%) & 81 & 70 & 65 & 59 & 34 & 41 & 44 & 40 & 50 \\
\hline E (\%) & 1 & 1 & 1 & 6 & 22 & 22 & 18 & 18 & 9 \\
\hline Hemoglobin (g/dL) & 11.2 & 10.9 & 10.8 & 10.0 & 9.5 & 10.1 & 10.9 & 10.9 & 10.0 \\
\hline Platelets $\left(10^{6} / \mathrm{mm}^{3}\right)$ & 219 & 430 & 400 & 293 & 202 & 208 & 281 & 302 & 290 \\
\hline \multicolumn{10}{|l|}{ Inflammatory } \\
\hline $\mathrm{CRP}(\mathrm{mg} / \mathrm{l})$ & 231 & 56 & 29 & 16 & 78 & 102 & 68 & 32 & 8 \\
\hline ESR mm/first hour & 100 & 95 & 88 & 68 & 95 & 90 & 78 & 70 & 56 \\
\hline \multicolumn{10}{|c|}{ Transthoracic two-dimensional echo } \\
\hline Vegetation & Yes & Yes & Yes & Yes & No & No & No & No & No \\
\hline Size (mm) & $7 \times 13$ & $7 \times 10$ & $6 \times 10$ & $4 \times 8$ & - & - & - & - & - \\
\hline
\end{tabular}

CRP C-reactive protein, E eosinophils, echo echocardiography, ESR erythrocyte sedimentation rate, $I V$ intravenously administered, $N$ neutrophils, $W B C$ white blood cells 
phosphatase (ALP) $136 \mathrm{IU} / \mathrm{ml}$. We omitted intravenously administered cloxacillin and kept him without antimicrobials while arranging a septic screening with a close observation of clinical parameters, WBC/DC, and inflammatory markers. His blood picture showed leukopenia with profound neutropenia and he had eosinophilia. Red blood cells and platelets were normal. He was clinically well and on day 6 after stopping cloxacillin, white blood cells (WBC) became normal with $44 \%$ neutrophils and $18 \%$ eosinophils. Liver function tests also returned to normal after cloxacillin discontinuation. He was treated with anti-pyretic as required. Subsequently, his septic screening became negative and transthoracic two-dimensional echo showed complete healing with no vegetations.

His serum was negative for filarial and Toxoplasma antibodies while stool was negative for oocytes and amoebic cysts. Further, his serum was negative for Epstein-Barr virus, cytomegalovirus, and hepatitis B antibodies. Subsequently his CRP and ESR became normal, and there was no further plan for cardiothoracic intervention or administration of antimicrobials. He was discharged from hospital and remained well 6 months later.

\section{Discussion}

IE if left untreated is almost inevitably fatal. Prognosis mainly depends on whether or not complications develop. Early detection and appropriate treatment of this uncommon disease can be lifesaving. The overall mortality rate has remained stable at $14.5 \%$. To eradicate the bacteria that remain inside the vegetation in IE requires prolonged and high-dose antimicrobial treatment. For communityacquired MSSA infection in individuals who do not abuse intravenously administered drugs, the cure rate is $60-70 \%$ [7].

Neutrophils are a type of immune cell, termed granulocytes, and they are the first cell types to travel to the site of an infection. Neutrophils help fight infection by ingesting microorganisms and releasing enzymes that kill the microorganisms. Agranulocytosis is a marked and profound decrease in the number of granulocytes, or an absolute lack of granulocytes in circulating blood, typically resulting in a neutrophil count below $0.5 \times 10^{9} / \mathrm{L}$ [8]. Most cases $(70-90 \%)$ of agranulocytosis are caused by viral infections, drugs (drug or its metabolites), chemotherapy, and radiotherapy [9]. Beta lactams and especially penicillins have been reported to cause agranulocytosis since 1946 [10], and have long been associated with the inhibition of granulopoiesis. A few antibiotics other than beta lactam, such as linezolid, trimethoprim-sulfamethoxazole, clindamycin, gentamycin, and chloramphenicol, are known to cause agranulocytosis [11]. Simultaneously, development of eosinophilia signifies parasitic infestation or development of hypersensitivity or both.

In this case scenario, we had a fair amount of doubt about the definitive cause of the emergence of pyrexia and the hematological discrepancy. Top of the list was MSSA relapse, new infection with methicillin-resistant Staphylococcus aureus (MRSA) or different Gram-negative bacteria or viral agent, or parasitic infestation leading to pyrexia with leukopenia and eosinophilia. Often, isolated bacterial, viral, or parasitic infections do not produce a combined picture of neutropenia with eosinophilia. In parasitic infestation, eosinophilia can develop without neutropenia, whereas in viral infections, neutropenia can develop without eosinophilia [12]. Co-infection of viral and parasitic agent can lead to the above picture [13]. However, we excluded common viral infections and parasitic infestations which are endemic in Sri Lanka. A repeat transthoracic two-dimensional echo was normal and excluded the possibility of valvular or myocardial abscesses. Also, his D-dimer, PTT, and PT were normal; the possibility of disseminated intravascular coagulation was excluded.

Following omission of cloxacillin and our patient's significant recovery with subsiding fever and normalizing of his hematological parameters, our attention was directed toward adverse drug reactions. The impact of this case report is that it signifies the potential fatal adverse effect of a commonly used antimicrobial in MSSA infections: cloxacillin. Often this phenomenon is associated with prolonged use of high doses. A case report in 2014 described the use of cloxacillin in a patient with MSSA-IE and agranulocytosis developed in 20 days of therapy [6]. In our case it was after 24 days and the total dose was $288 \mathrm{~g}$ of cloxacillin. It was postulated that total dose of $>150 \mathrm{~g}$ was associated with the development of neutropenia [6]. Our patient was on intravenously administered ceftriaxone as well but it was given over 2 days thus the effect could be negligible.

The exact pathogenesis behind the leukopenia was less understood and two mechanisms were proposed: direct toxic effect of the drug, and immunological allergic reaction and creation of neutrophil antibodies. This patient developed leukopenia associated with neutropenia while hemoglobin and platelets remained normal. This reflects suppression only in granulocyte axis of cell genesis. Also, during the leukopenia phase our patient had eosinophilia which suggests immune-mediated hypersensitivity $[6,14]$.

Although this is a rare phenomenon, awareness among clinicians of such adverse reactions would alert them to assess the patient periodically with serial WBC/DC. In the documented cases, including this case, the patients only developed high grade fever with high CRP and did not develop neutropenic sepsis [6]. Also, once cloxacillin was omitted WBC/DC became normal. The prolonged use of cloxacillin with high dose in clinical practice is quite common, but the occurrence of agranulocytosis is quite rare. For development of agranulocytosis there could be an existing genetic predisposition for the 
development of cloxacillin-induced hypersensitivity or drug-induced myelotoxicity.

In IE, prolonged (28-42 days) intravenously administered antibiotics are required to eradicate the microbes within the cardiac vegetation. Here, following early and appropriate therapy, our patient became afebrile and clinically stable. When febrile neutropenia develops, clinicians often tend to prescribe granulocyte colony-stimulation factor (GCSF) to stimulate granulocyte formation. This was practiced commonly among patients with cancer with IE. Here, however, the probable cause of neutropenia was drug induced and therefore we omitted the offending agent and did not give GCSF $[9,15]$.

\section{Conclusion}

Prolonged administration of cloxacillin with high doses could lead to the development of leukopenia which puts patients at risk of developing neutropenic sepsis. Vigilant attention on blood WBC/DC would help clinicians to identify the leukopenia early and withdraw the cloxacillin. In addition to transthoracic two-dimensional echo, CRP, ESR, and sequential WBC/DC would help clinicians to assess the prognosis of patients with IE.

\section{Abbreviations}

ALP: Alkaline phosphatase; ALT: Alanine transaminase; CRP: C-reactive protein; Echo: Echocardiography; ESR: Erythrocyte sedimentation rate; GCSF: Granulocyte colony-stimulation factor; IE: Infective endocarditis; MRSA: Methicillin-resistant Staphylococcus aureus; MSSA: Methicillin-sensitive Staphylococcus aureus; PT: Prothrombin time; PTT: Partial thromboplastin time; WBC: White blood cells; WBC/DC: White blood cell/differential counts

\section{Acknowledgements}

We would like to acknowledge the medical staff who were involved in the provision of care for this patient.

\section{Funding}

Non-funded study

\section{Availability of data and materials}

The datasets supporting the conclusions of this article can be obtained following a request.

\section{Authors' contributions \\ JAASJ, WPHA, and GRR conducted clinical examination and treatment intervention. WPHA, JAASJ, and GRR performed the microscopy and identification of blood culture isolate. JAASJ and WPHA drafted the manuscript; WPHA, JAASJ, and GRR reviewed the manuscript. All authors read and approved the final manuscript.}

\section{Ethics approval and consent to participate}

Ethical approval was obtained from institutional ethical review committee, Teaching Hospital Kurunegala, Sri Lanka. Informed consent for the participation was obtained from the patient.

\section{Consent for publication}

Written informed consent was obtained from the patient for publication of this case report and any accompanying images. A copy of the written consent is available for review by the Editor-in-Chief of this journal.

\section{Competing interests}

The authors declare that they have no competing interests.

\section{Publisher's Note}

Springer Nature remains neutral with regard to jurisdictional claims in published maps and institutional affiliations.

Received: 3 November 2017 Accepted: 25 November 2018

Published online: 29 December 2018

\section{References}

1. Eggimann P, Pittet D. Acute bacteraemia. In: Fink MP, Abraham E, Vincent J, Kochanek P, editors. Textbook of critical care. Philadelphia: Elsevier Saunders; 2005. p. $1275-83$.

2. Lyytikainen O, Ruotsalainen E, Jarvinen A, Valtonen V, Ruutu P. Trends and outcome of nosocomial and community-acquired bloodstream infections due to Staphylococcus aureus in Finland, 1995-2001. Eur J Clin Microbiol Infect Dis. 2005:24:399-404.

3. Benfield T, Espersen F, Frimodt-Moller N, Jensen AG, Larsen AR, Pallesen LV, et al. Increasing incidence but decreasing in-hospital mortality of adult Staphylococcus aureus bacteraemia between 1981 and 2000. Clin Microbiol Infect. 2007;13:257-63.

4. Rieg S, Peyerl-Hoffmann G, de With K, Theilacker C, Wagner D, Hubner J, et al. Mortality of $S$. aureus bacteremia and infectious diseases specialist consultation-a study of 521 patients in Germany. J Inf Secur. 2009;59:232-9.

5. Wijesekara PNK, Kumbukgolla WW, Jayaweera JAAS, Rawat D. Review on Usage of Vancomycin in Livestock and Humans: Maintaining Its Efficacy, Prevention of Resistance and Alternative Therapy. Vet Sci. 2017;4:6.

6. Wong KW. Intravenous Cloxacillin Induced Agranulocytosis in a Haemodialysis Patient. Gen Med (Los Angel). 2014;2:142. https://doi.org/10. 4172/2327-5146.1000142.

7. Bor DH, Woolhandler S, Nardin R, Brusch J, Himmelstein DU. Infective endocarditis in the USA 1998-2009: a nationwide study. PLoS One. 2013;8(3): e60033.

8. Andrès E, Zimmer J, Affenberger S, Federici L, Alt M, et al. Idiosyncratic drug-induced agranulocytosis: Update of an old disorder. Eur J Intern Med. 2006;17:529-35.

9. Andrès $\mathrm{E}$, Zimmer J, Mecili $\mathrm{M}$, Weitten T, Alt M, et al. Clinical presentation and management of drug-induced agranulocytosis. Expert Rev Hematol. 2011:4:143-51.

10. Spain DM, Clark TB. A case of agranulocytosis occurring during the course of penicillin therapy. Ann Intern Med. 1946;25:732.

11. Apinantriyo B, Lekhakula A, Rujirojindakul P. Incidence, etiology and bone marrow characteristics of non-chemotherapy-induced agranulocytosis. Hematology. 2011;16:50-3.

12. Weatherall DJ, Kwiatkowski D. Hematologic manifestations of systemic diseases in children of the developing world. In: Nathan D, Orkin, editors. Hematology of Infancy and Childhood. 5th ed. Philadelphia: WB Saunders; 2012. p. 1902.

13. Esposito DH, Stich A, Epelboin L, et al. Acute muscular sarcocystosis: an international investigation among ill travelers returning from Tioman Island, Malaysia, 2011-2012. Clin Infect Dis. 2014;59:1401.

14. Tanous $\mathrm{O}$, Hayek T, Hamoud S. Transient Cloxacillin Induced granulocytosis with Eosinophilia and Elevated lgE Levels. Gen Med (Los Angel). 2013;1:111.

15. Borgbjerg BM, Hovgaard D, Laursen JB, Aldershvile J. Granulocyte colony stimulating factor in neutropenic patients with infective endocarditis. Heart. 1998;79(1):93-5.

Ready to submit your research? Choose BMC and benefit from:

- fast, convenient online submission

- thorough peer review by experienced researchers in your field

- rapid publication on acceptance

- support for research data, including large and complex data types

- gold Open Access which fosters wider collaboration and increased citations

- maximum visibility for your research: over 100M website views per year

At BMC, research is always in progress.

Learn more biomedcentral.com/submission 